\title{
Soil management in the urban environment: today and future
}

\author{
BOGDAN STANESCU, ADRIANA CUCIUREANU
}

National Research and Development Institute for Industrial Ecology ECOIND Bucharest, 71-73 Drumul Podul Dambovitei, 060652, Bucharest, Romania

*correspondence author (e-mail): stanescubogdan2@gmail.com

The present article presents the expertise realized by the Department of Environmental Monitoring Pollution Evaluation within the INCD ECOIND, in the evaluation of the quality of urban soils in the municipality of Bucharest and the main big cities in Romania. The current data available at the level of the 27 member states of the European Union show that annually over 100,000 hectares of land are introduced into the urban environment, a direct consequence of the development of cities. There are a number of legislative obstacles to strategic soil protection measures. Moreover, at the level of the local authorities there is a conflict regarding the measures of soil protection in the long term, on the one hand, and, the accelerated economic development in the short term, on the other. European environmental experts consider that the urban development, absolutely necessary for the economic growth, requires an adequate management of the natural resources in order for the development to be done on a sustainable basis, respectively to follow a series of strategic objectives. In our country, at least in the last decade, we find on a large scale the conversion of industrial areas into commercial or residential areas. The footprint of industrial activities can be found even after long periods of time present by identifying the remnant of soil pollution or in those areas known as historically polluted (for example the town of Copsa Mica).

The conclusions stemming from the assessment of pollution in urban areas over large areas, in correlation with the potential sources of pollution, underline the need to monitor the quality of soils in the urban environment, but also to apply a performance management in order to protect this natural resource in the long term.

Keywords: assessment, urban soil, pollution, management

The activities presented in this article aimed at the level of the main cities in Romania: Iasi, Timisoara, Cluj Napoca, Constanta, Craiova, Galati, Brasov, Ploiesti and Oradea to highlight the quality of the soils in the urban environment. Urban ecology studies show that soil pollution is especially important because it is directly related to public health. The increase of the population density in the urban environment is felt by the influence of the anthropic activities and on the quality of the soils (mainly the industrial activities). It is found that urban soils differ greatly from natural ones, respectively from those not found under the direct influence of the anthropic factors in the big cities.
Urban soils accumulate different types of pollutants from different sources of pollution.

The development of cities in Romania has undergone major changes in the last decades, whether we are talking about the rehabilitation of the existing infrastructure or the construction of new infrastructure, or the restriction of industrial areas and, very important, their conversion into commercial or residential areas. Soil is at the same time a very important natural resource that must be kept under sustainable conditions for future generations.

Figure 1 shows the cities in Romania that were investigated within the project for evaluating the quality of urban soils. 


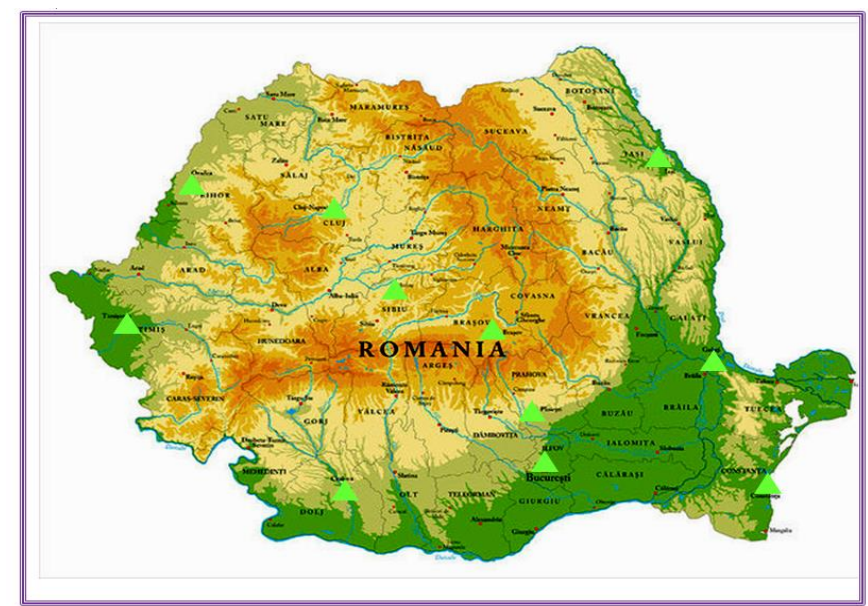

Fig.1. City soil investigations on physical map of Romania

It is known that the urban population is constantly growing. Currently, estimates show 50 per cent of the world's population is concentrated in the urban environment and the trend is increasing by up to 70 per cent in 2050 [1]. It is found that urban areas are growing continuously, and the growth rate is faster than any other land use, respectively land intended for urbanization [2]. Therefore, the importance of green spaces in the urban environment with their ecosystem functions and services is beginning to become more and more important to the sustainability of the environment in urban areas [3]. Manageable soil properties including the changes caused by additions in soil conditions [4] and vary across the landscapes [5, $6,7]$. Soil natural capital needs to be quantified in such a way that it can be integrated into environmental policy and land management decision-making to inform the provision of ecosystem services [8]. Figure 2 presents graphically a series of problems, ranked according to their importance, in direct connection with the quality of the soils in urban zones [9].

The role of soil in the urban environment is an essential role in the development of the human society. Public awareness is focused on soil as a basis for space for housing, industrial and commercial purposes as well as infrastructure, recreation areas and food production.

The main soil services in the urban environment is shown in figure 3 .

It is important to mention that the processes related to the water cycle in the urban environment are deteriorated, especially the buffer function represented by the soil cover in relation to the precipitation, respectively the main meteoric waters are drained and can produce floods and only a small part it infiltrates the soil, in the unsaturated area, without ensuring recharge of the groundwater.

In the current stage there is a lack of information of the population regarding the importance of the soil and of its functions in the urban environment, therefore the importance of the soil is greatly diminished from the attention of the general public.

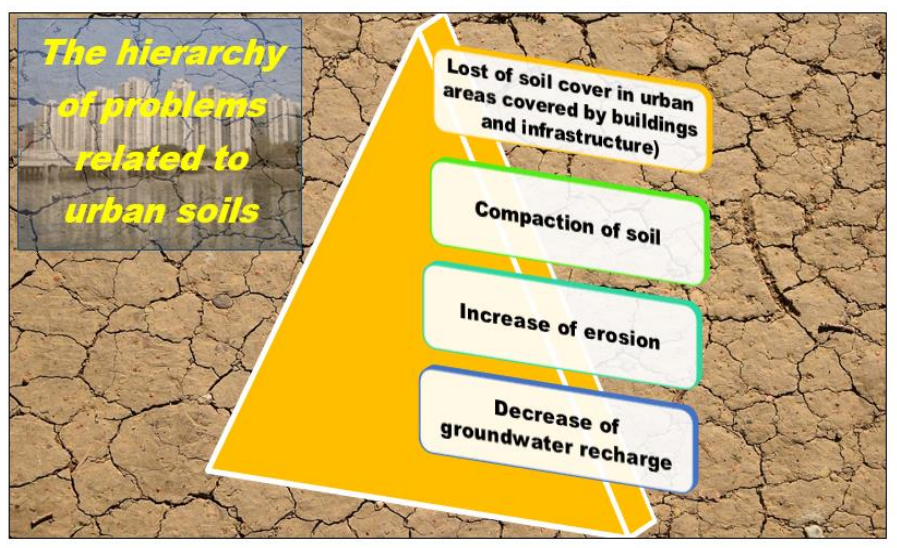

Fig.2. Problems hierarchy regarding soil quality in urban zones 


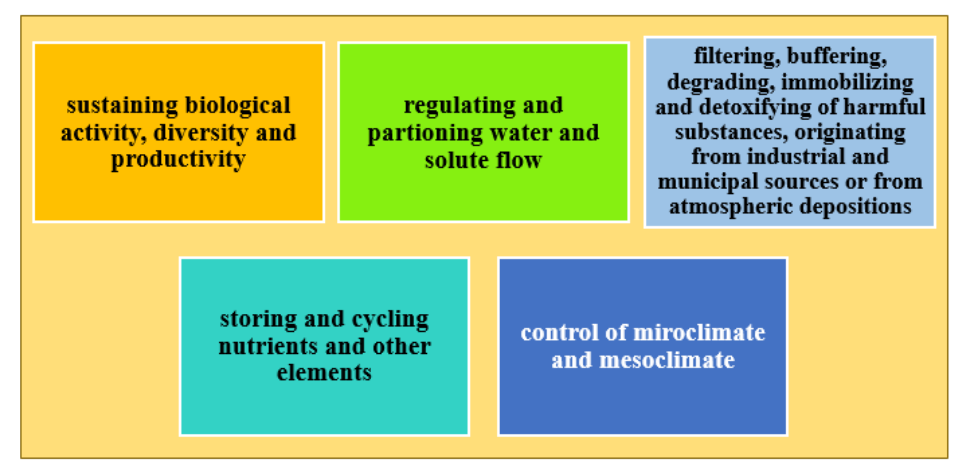

Fig. 3. Soil services in the urban environment

Soil management is a priority to protect this resource so important, especially in the urban environment where the anthropic pressures are very high. It is absolutely mandatory to take into account the relationships between soil and human health, as well as between soil and climatic conditions, respectively the adaptation to climate changes of the last decades.

\section{EXPERIMENTAL PART}

The location of study areas on the maps are presented in Figure 1. Activites was conducted in two main directions:

\section{A. Field activities:}

- dimensioning the number of samples to soil to be sampled with adequate equipment for sampling;

- obtaining relevant information and details (microrelief, hydrographic network, climatic influences, industrial pollution sources in each city studied, land use and functionallity, etc);

- GPS localizations of the samples and maps of the experimental field for each city.

\section{B. Laboratory activities:}

- relevant quality indicators determined by modern analytical techniques (ICP-MS);

- adequate test methods, standardized and validation of the results using Certified References Materials.

Figure 4 shows schematically the activities carried out for investigating the quality of urban soils.

It is noted that the in terrain documentation activities occupy the first place, especially important, because the office documentation cannot supplement the updated information's obtained on the site.

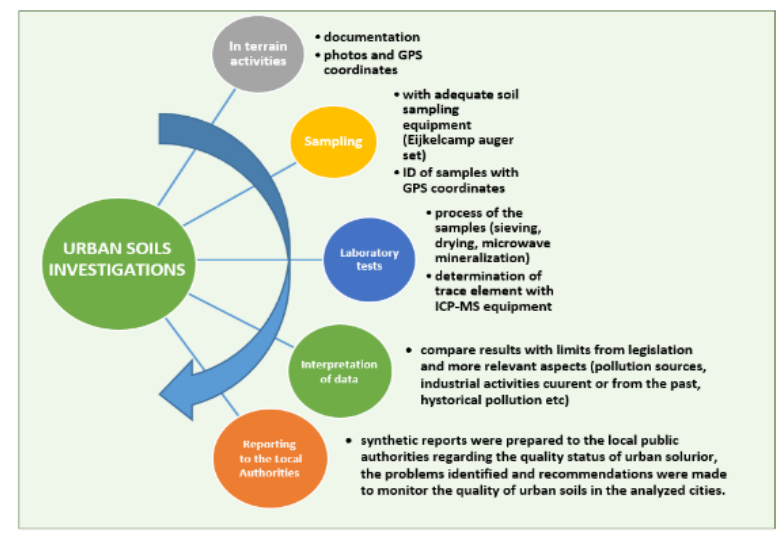

Fig.4. Scheme for conducting soil survey in urban areas

The involvement of local public authorities with competences in ensuring the quality of the environmental conditions in urban areas is defining and necessary. That is why the final report of the obtained results is directed to them, it is a processed information by specialists on environmental assessment who make a series of recommendations and monitoring proposals for future stages, practically a contribution and a support for the realization of management on soil resources in the urban environment. 


\section{RESULTS AND DISCUSSION}

The most important aspects related to the chemical pollution of the soils in the analyzed cities, especially heavy metal pollution, reveal a series of details that highlight the specific mark of each analyzed city. For example, in Iasi city, 32 soil samples were collected and analyzed from the top soil layer, the first $10 \mathrm{~cm}$. of the 11 quality indicators analyzed, from the heavy metals category were analyzed: total chromium, lead, copper and zinc. All the results obtained were compared with the reference values contained in Order 756 of November 3, 1997 [10] for approving the Regulation regarding the assessment of environmental pollution.

For the city of Iasi, there is a significant, historical pollution, the remanent from the periods of intense activity of some large economic units with industrial profile that worked in the city of Iasi, such as "Tepro" (metallurgical profile), the "Heavy Equipment Facility" and "Terom SA"; thus the recorded pollution is located in the industrial area of the city of Iasi with exceeding the intervention threshold at the indicator "zinc".

Another example, for the city of Timisoara, which does not have an industry concentrated in a single area, soil pollution was reported only punctually (1 sample out of 29 analyzed), without a define a correlation with the industrial sources of pollution.

In the city of Cluj-Napoca the experimental field consisted of 21 soil samples scattered throughout the city, and the analytical results obtained revealed only exceedances of the alert thresholds for lead, cadmium and total chromium in different point areas (in the city of Cluj Napoca in one the area with a filling land used for the arrangement of a commercial outdoor green space).

In the city of Constanta heavy metal pollution was identified in a degraded urban area where household waste was stored. A similar situation was identified in the city of Ploiesti. There are local problems identified as important issues, which are still partially solved, the existence of these degraded areas where uncontrolled waste is stored. Unfortunately, these areas are not always inventoryed and, therefore, there is no prompt intervention to restore the quality conditions acceptable to the soil.

What is appreciated is the fact that local authorities want to stop this phenomenon and eliminate it in the near future.

A special study case belongs to the city of Copsa Mica, a small city, but with a very polluting industry that has been active for over 8 decades. There were identified a number of negative aspects regarding the quality of the soils, which consist in the frequent exceedance of the intervention threshold.

An extremely unfavorable situation was recorded in an area located near DN14 B, at approx. $700 \mathrm{~m}$ southbound from the dumps of the company Sometra SA, which is the main potential source of heavy metal pollution. As a general conclusion for the soil environment component: the soil is still affected by the remaining pollution, of historical character, induced by the industrial activities carried out in the area for long periods of time, which had a significant impact on the environment (Figure 5). In Craiova city the heavy metal pollution induced by the values of the copper quality indicator was identified near the industrial area represented by the industrial platform Electroputere and SC MAT SA Craiova. Also, the values that exceeded the alert threshold of copper lead and zinc quality indicators, were identified both in Craiova, as well as in the cities of Galati and Brasov, the latest metionated being also cities with a well represented industrial profile. The city of Oradea was shown with a good representation of the compliance of the quality conditions of the soil over in the urban environment, which is a noticeable and a positive fact. The capital of Romania, Bucharest has highlighted both the existence of degraded urban areas, marked by the uncontrolled wastes directly on soil, but also important exceedances of heavy metals in the soil in areas where metallurgical activities, highly polluting, such as "Laromet industrial platform", in the northern part of the city. Bucharest has major environmental problems related to road traffic, which brings a major contribution of pollution.Also, particulate matter pollution of the city atmosphere is a major source of soil pollution by direct deposits on the ground or through precipitation. 


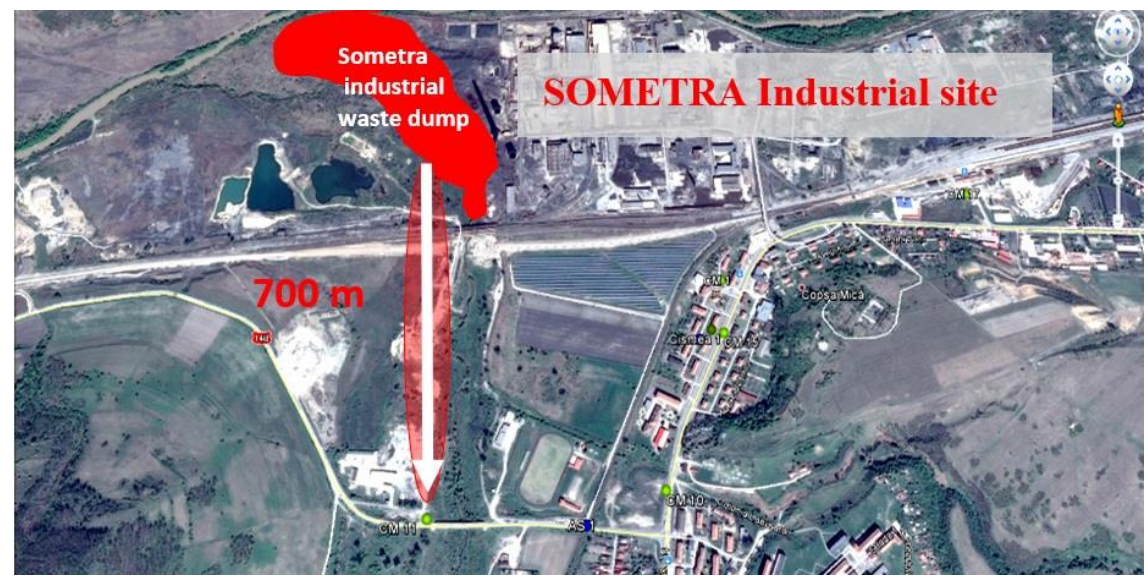

Fig .5. Pollution in Copsa Mica city related to actual potential source

\section{CONCLUSIONS}

Results obtained and the concrete situation in the investigated urban areas led to the following conclusions:

- to sensitize the general public on the importance of keeping good soil conditions in the cities of Romania;

- to actively involve the responsible factors, respectively the Local Public Authorities, to initiate soil monitoring programs in the urban environment in order to follow in time and with a large spatial distribution the evolution of the soil quality and to intervene promptly if problems that may affect soil quality are reported. Figure 6 shows a proposed model for approaching urban soil management for the best monitoring and protection of this important natural resource, soil. From the experience of other European countries that already took important steps in urban soil management, it was found that degraded areas, through an adequate strategy, were limited by implementing measures for high soil quality protection.

In the modern acceptance, soil protection is regarded as a source of maintaining the health of the environment, through its role to ensure the urban microclimate, to temper the thermal contrasts and to attenuate the circulation of fine powders. There is also an economic approach, because the costs of discharging the fluvial water through the drainage networks of the urban infrastructure can be greatly diminished if the soil in the urban environment allows the inflection, as close to the values specific to the natural environment.

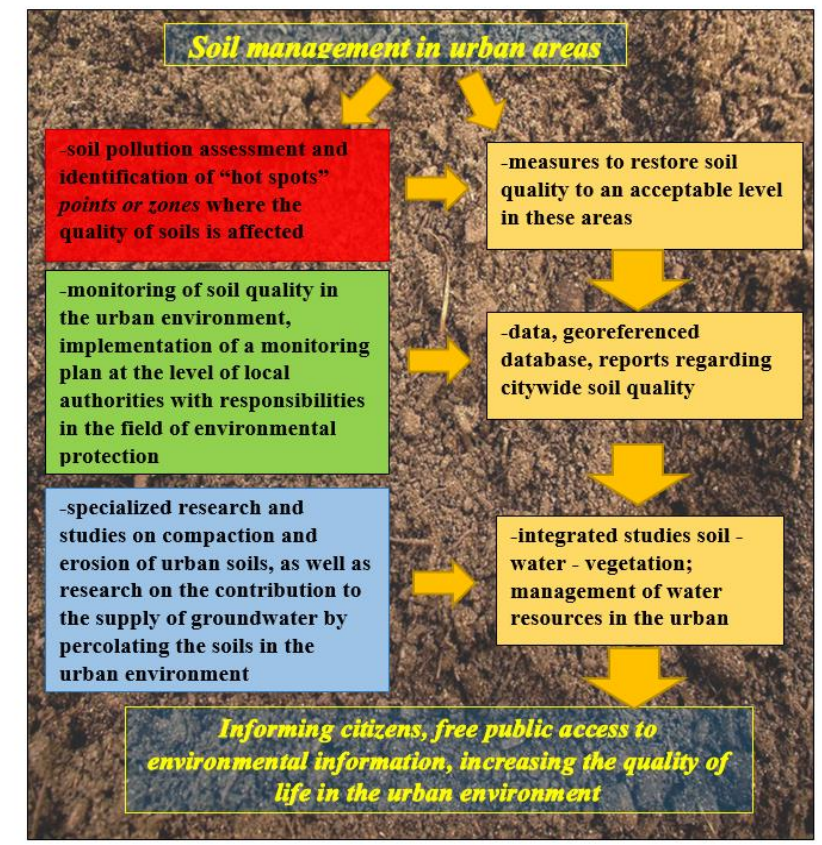

Fig. 6. Proposed model for Soil Management in urban areas 
ACKNOWLEDGEMENTS. This work was carried out through the "Program Nucleu", financed by the Ministry of Research and Innovation of Romania, project codes: PN 16250210 and PN 16250206.

\section{REFERENCES}

1. U.N. 2008. World urbanization prospects: the 2007 revision. New York, NY: United Nations.

2. ANTROP, M., Landscape Ecol., 15, 2000, p. 257.

3. BOLUND P., HUNHAMMAR S., Ecol. Econ., 29, 1999, p. 293.

4. MCBRATNEY, A., FIELD, D.J., KOCH, A., Geoderma, 213, 2014, p. 203.

5. SPARLING, G.P., SCHIPPER, L.A., J. Environ. Qual., 31, 2002, p. 1848.

6. SPARLING, G., SCHIPPER, L., Agric. Ecosyst. Environ., 104, 2004, p. 545.

7. SPARLING, G.P., SCHIPPER, L.A., BETTJEMAN, W., HILL, R., Agric. Ecosyst. Environ., 104, 2004, p. 523.

8. BRISTOW, K.L., MARCHANT, S.M., DEURER, M., CLOTHIER, B.E., Proc. 19th World Congress of Soil Science, Brisbane, Australia, 2010.

9. HUBER, S., VERNIK, T., SIEBIELEC, G., VRSCAJ, B., Soil in the City. Urban Soil Management Strategy, Book, 2012.

10. *** Order no. 756 of November 3, 1997 for approving the Regulation regarding the assessment of environmental pollution 